\title{
The role of butyrate in human colonic epithelial cells: an energy source or inducer of differentiation and apoptosis?
}

\author{
BY ANGELA HAGUE, ALISON J. BUTT \\ AND CHRISTOS PARASKEVA
}

\begin{abstract}
The CRC Colorectal Biology Tumour Group, Department of Pathology \& Microbiology, School of Medical Sciences, University of Bristol, University Walk, Bristol BS8 ITD
\end{abstract}

Colo-rectal cancer is a major health problem in industrialized countries and the high incidence has been linked with the diet (Burkitt, 1971). The colonic epithelium is in direct contact with dietary factors present in the lumen and these factors may affect the pattern of growth, differentiation and cell death within the tissue. Epidemiological studies suggest that a low-fat, high-fibre diet is protective for colo-rectal cancer (Burkitt, 1971; Howe et al. 1992) whereas a diet high in red meat and saturated fat and low in dietary fibre and vegetables is associated with an increased risk for colo-rectal cancer. Colon cancers most often develop from premalignant adenomas (sometimes referred to as polyps) which, in turn, are derived from the normal colonic epithelium. Sandler et al. (1993) conducted an epidemiological study which showed that diets high in fat and low in carbohydrates and fibre not only increased the risk for colo-rectal cancer, but also for the precursor adenomas. The diet, therefore, may be particularly important for those individuals predisposed to large-bowel cancer and a better understanding of how dietary factors may influence colon cancer risk may lead to dietary intervention.

Dietary fibre is composed of non-polysaccharides such as lignin and the NSP, carbohydrates such as cellulose, pectin and gums which are derived from plant cell walls. Fibre escapes digestion in the stomach and small intestine, as do oligosaccharides and some resistant starches (Silvester et al. 1995) but in the large bowel symbiotic bacteria are able to ferment these carbohydrates, releasing the short-chain fatty acids (butyrate, propionate and acetate) as a by-product of this metabolism.

There are a number of ways in which fibre could protect against colo-rectal cancer. It increases transit rate and bulk, thereby potentially decreasing exposure to carcinogens in the diet. It adsorbs carcinogens, modifies intestinal microflora (and may, therefore, alter bile salt and carcinogen metabolism), decreases faecal bile salt excretion and lowers the colonic $\mathrm{pH}$, as well as increasing the concentrations of the short-chain fatty acids in the large bowel (McIntyre et al. 1993). The diet is complex, and in epidemiological studies it is difficult to unravel the effects of individual components. For example, diets high in animal fat may also contain carcinogens generated during cooking of meat. Diets low in fruit and vegetable fibre may be low in vitamins which have antioxidant effects (for review, see Rogers et al. 1993). Animal studies have helped in this respect in that diets can be more carefully controlled, but the results are variable because of the types of fibre administered (Levin, 1992). Dietary wheat bran results in higher concentrations of butyrate than either oat bran or guar gum (Kashtan et al. 1992; McIntyre et al. 1993).

\section{BUTYRATE AS AN ENERGY SOURCE AND INDUCER OF DIFFERENTIATION}

The production of short-chain fatty acids by the colonic bacteria is of significance to the 
colonic epithelium, since these by-products can be metabolized by the colonic epithelium to produce ketones, $\mathrm{CO}_{2}$ and energy, and there is evidence that butyrate may be the preferred energy source of the colonic epithelium over glucose or glutamine (Roediger, 1982). Indeed, butyrate may account for $70 \%$ of the total energy consumption of the colonocyte (Scheppach, 1994). In vitro studies have shown that in colo-rectal tumour cell lines butyrate inhibits cell proliferation and induces a more differentiated phenotype (Augeron \& Laboisse, 1984; Whitehead et al. 1986; Deng et al. 1992; Gamet et al. 1992). Butyrate is used in the treatment of ulcerative colitis, restoring the normal balance of proliferation and differentiation in the colonic crypt (Scheppach et al. 1992). It has been considered as a potential therapy for colo-rectal cancer, and it has been suggested that butyrate could be targeted to carcinoma cells using a tumour-specific monoclonal antibody to deliver a measured dose in a liposome capsule (Otaka et al. 1989).

Butyrate has two contrasting roles: as an energy source for normal colonic epithelium and as an inducer of differentiation in malignant cells. Jass (1985) hypothesized that the shift from aerobic to anaerobic metabolism during colo-rectal carcinogenesis may interfere with the oxidation of butyrate. The resultant accumulation of butyrate within the cell cytoplasm may explain why malignant cells are sensitive to the differentiating effects of butyrate. The cells would be less dependent on butyrate as a respiratory fuel. Furthermore, it could be an initial deficiency in levels of butyrate coupled with increased energy requirements of the neoplastic tissue which promote the switch to anaerobic metabolism (Jass, 1985).

\section{APOPTOSIS AND THE MAINTENANCE OF NORMAL CELL NUMBERS IN THE COLON}

Since in colo-rectal tumour cells, butyrate induces a differentiated phenotype, we questioned whether it was also capable of inducing apoptosis in these cells as apoptosis may represent the terminal stage of colonic epithelial cell differentiation pathways (discussed on p. 939). Apoptosis is a physiological process by which cells effectively commit suicide. Apoptosis is characterized by morphological changes including loss of cell-cell contact, loss of cell-matrix adhesion, cell shrinkage, loss of microvilli and chromatin condensation (Arends \& Wyllie, 1991). The chromatin forms dense crescent shapes lining the nuclear membrane, but the membrane then breaks down and the chromatin mass subsequently fragments. The plasma membrane becomes convoluted and the cell separates into a cluster of membrane-bound 'apoptotic bodies'. In vivo these are normally phagocytosed by macrophages or neighbouring cells. In many tissues undergoing rapid turnover of cells apoptosis is involved in the maintenance of tissue homeostasis. In the gut, where the epithelial cells are exposed to dietary carcinogens, cells undergo apoptosis as a means of eliminating damaged cells and, thus, protecting the tissue against neoplastic change. This has been demonstrated in animal models using various mutagenic compounds and also $\gamma$-radiation (Potten et al. 1992; Clarke et al. 1994; Merritt et al. 1994). Apoptosis in response to DNA damage may be p53-dependent, occurring rapidly after damage (Clarke et al. 1994; Merritt et al. 1994), or may be independent of p53 and occur as a later response (Bracey et al. 1995). The gastrointestinal tract is exposed to a wide variety of genotoxicants in the diet. These may be natural plant toxins, contaminants, or may be produced during cooking (Chadwick \& George, 1992). 
In addition, apoptosis may also be in part responsible for the removal of cells at the top of the crypts. The colonic epithelium is a dynamic tissue in a state of continual renewal. Cells proliferate in the lower two-thirds of the normal colonic crypt and cease division as they migrate further up the crypt. The continuous movement of cells up the colonic crypt is tightly linked to differentiation. The fate of the cells as they reach the top of the crypt is a matter of some controversy as the process is poorly understood. Exfoliation could be due to a passive sloughing off of cells, perhaps due to physical forces exerted by cells migrating up from below, or due to an active programmed cell death process. Loss of cell-cell contact is an early stage in the apoptotic process and, therefore, apoptosis may be used as a mechanism by which cells detach from the tissue into the lumen. Since in the colon there is a clear route of exit of apoptotic cells into the lumen, it is possible that such cells are rarely phagocytosed at the top of the crypt. Therefore, the apoptotic cells may not be obvious at the luminal surface.

The first evidence that apoptosis occurs at the top of the crypt came from in situ endlabelling studies demonstrating DNA fragmentation towards the luminal surface (Gavrieli et al. 1992). However, Bicknell \& Cohen (1995) have reported that kilobase DNA fragmentation may also occur during some forms of necrosis. They suggest that morphological analysis for apoptotic cells should confirm the apoptotic nature of the cell death. This evidence has been provided by Hall et al. (1994) in a careful study in which they counted morphologically apoptotic cells within colonic crypts and showed that apoptosis occurs chiefly in the upper two-fifths of the crypt. Given that the estimated in vivo life of an apoptotic cell is $1 \mathrm{~h}$, the rate of apoptosis could entirely offset the rate of new cell birth in the crypt (Hall et al. 1994). A disruption of this balance between cell gain through mitosis and cell loss through programmed cell death may be an important contributory factor in colo-rectal carcinogenesis.

The trigger for apoptosis at the luminal surface may be one of a number of changes in the local environment. In most tissues cell survival depends on a constant supply of survival signals (Raff, 1992) which may be provided by neighbouring cells or extracellular matrix components in addition to the systemic circulation. In the colon there is the possibility that these may also originate in the lumen.

\section{BUTYRATE INDUCES APOPTOSIS IN COLO-RECTAL TUMOUR CELL LINES}

Epithelial cell culture models provide a useful system for studying apoptosis, since in culture, cells undergoing apoptosis also detach from the substrate in a manner analogous to the in vivo situation, allowing apoptotic cells to be collected from the culture medium and analysed. Such cell culture systems permit the study of the effects of endogenous and exogenous factors on proliferation, differentiation and apoptosis, and on gene expression. They also permit the study of the events leading to cell detachment. In culture, colo-rectal tumour cells undergo apoptosis spontaneously, and the level of apoptosis varies between individual cell lines. By examining the effects of physiologically-obtainable levels of butyrate $(2-4 \mathrm{mM})$ on cell lines derived from colonic adenomas and carcinomas, we showed that butyrate can induce apoptosis (Hague et al. 1993). The apoptotic cells are shed into the culture medium, and the floating cells show the classic apoptotic morphology of condensed chromatin and characteristic DNA fragmentation pattern of multiples of 200 base pairs (Wyllie, 1980). In the seven cell lines tested for their response to sodium 
butyrate, all exhibited apoptosis after treatment (Hague et al. 1995). However, two of the carcinoma cell lines were relatively resistant to butyrate. A subset of carcinomas, therefore, may be resistant to butyrate-induced apoptosis. It will be important to determine the mechanisms by which this resistance is achieved, in addition to investigating how butyrate induces apoptosis in cells. Heerdt et al. (1994) demonstrated elevated alkaline phosphatase (EC 3.1.3.1) activity in a carcinoma cell line treated with sodium butyrate. Alkaline phosphatase is a commonly used marker of differentiation. Interestingly, the floating apoptotic cells induced by butyrate had increased levels of alkaline phosphatase activity compared with the adherent cell population, an observation suggesting that apoptosis occurred subsequent to differentiation. We have found similar results in floating apoptotic cells from butyrate-treated adenoma and carcinoma cultures. Furthermore, butyrate also increases the expression of E-cadherin protein, another marker of colonic epithelial cell differentiation, in colo-rectal adenoma cells (A. J. Butt and C. Paraskeva, unpublished results). The finding that butyrate induces apoptosis, apparently via terminal differentiation, provides evidence that for colonic epithelial cells apoptosis may form the culmination of a differentiation pathway and this may be analogous to the in vivo situation.

We also examined whether propionate and acetate could induce apoptosis in three colorectal tumour cell lines, $\mathrm{AA} / \mathrm{C} 1, \mathrm{RG} / \mathrm{C} 2$ and $\mathrm{PC} / \mathrm{JW} / \mathrm{FI}$. Both sodium propionate and sodium acetate induced apoptosis, but to a lesser extent than butyrate (Hague et al. 1995). Acetate was the least effective, but did induce apoptosis at concentrations of $40 \mathrm{mM}$ and above. This is in accordance with the differential effects of the three short-chain fatty acids in terms of inhibiting proliferation and inducing differentiation (Whitehead et al. 1986; Gamet et al. 1992). In the colon, the molar ratios of acetate:propionate:butyrate are $57: 22: 21$, and the concentration of acetate in the colonic contents may reach $60 \mathrm{mmol} / \mathrm{kg}$ (Cummings et al. 1987). These levels are not constant, but vary according to the substrates fermented (Scheppach et al. 1995). It may be, therefore, that the concentrations of acetate required to induce apoptosis would be physiological. Of further interest, in our studies (Hague et al. 1993, 1995) and that of Heerdt et al. (1994), butyrate-induced apoptosis was manifested as floating apoptotic cells, and no increase in apoptosis was detected in the adherent cells. In contrast to these findings, propionate induces apoptosis which is detectable in the adherent cells. The reason for the later detachment of the cells after treatment with propionate is as yet unknown, but the answer may lie in the different metabolism of those short-chain fatty acids with an odd number of $\mathrm{C}$ atoms. Propionate may prove to be a useful tool for the investigation of apoptotic pathways since it permits the study of the earlier stages of apoptosis. Up to 50\% apoptosis can be obtained in the adherent cells, and many of these are in the early stages of apoptosis where the nuclear membrane remains intact and the chromatin forms dense crescent shapes lining it.

\section{APOPTOSIS, p53 AND Bcl-2}

It is of note that the three short-chain fatty acids, butyrate, propionate and acetate, induce apoptosis in cell lines which have no p53 protein, or which have mutant p53 only (Hague et al. 1993, 1995). p53, therefore, is not required for the induction of apoptosis by the shortchain fatty acids. This is further evidence that p53-dependent apoptosis in response to DNA damage occurs by a separate pathway to that occurring via terminal differentiation. To further our understanding of the mechanisms by which butyrate induces apoptosis, we are investigating its effects on the expression of the Bcl-2 family of proteins. 
Bcl-2 was discovered as a result of the 14;18 translocation in follicular lymphoma (Tsujimoto et al. 1985). In this case overexpression of Bcl-2, due to its abnormal control by the immunoglobulin heavy-chain enhancer, produces B cells with an extended survival capacity. Bcl-2 is now known to be protective against apoptosis in many diverse tissue types. In the colon, Bcl-2 is largely confined to the base of the crypts (Hockenbery et al. 1991; Hague et al. 1994). In contrast, Bax, the death promoter, is expressed largely in the upper half of the crypt, along with death protectors characteristic of fully-differentiated cell types, Bcl-x and Mcl-1 (Krajewski et al. 1994a,b, 1995). The gradient of distribution of proteins of the Bcl-2 family up the colonic crypt is indirect evidence that programmed cell death is an integral mechanism by which the crypt length is kept constant. We are using our in vitro model system to determine the effects of butyrate and other differentiation agents on the expression of the Bcl-2 family of proteins. We have found decreased levels of $\mathrm{Bcl}-2$ protein in cells exposed to butyrate under conditions where apoptosis is induced; however, there is no change in the level of the Bax protein (A. Hague and C. Paraskeva, unpublished results). This decrease in Bcl-2:Bax may be involved in promoting apoptosis in response to sodium butyrate.

Having shown that butyrate is capable of inducing apoptosis in vitro in both premalignant and malignant tumour cells of colonic origin, we need to develop a greater understanding of the effects of butyrate on normal colonic epithelial cells. For example, although butyrate is considered to be an energy source for normal colonic epithelium, we do not know whether differentiation and apoptosis are the end-point of butyrate metabolism in normal colonic epithelial cells. Of importance to the consideration of butyrate in a therapeutic regimen is the question as to whether there is a differential response, i.e. are tumour cells more sensitive to butyrate-induced apoptosis than normal cells? Are normal cells more capable of metabolizing butyrate to produce energy? If tumour cells are more sensitive to butyrate-induced apoptosis than normal cells, this may have important implications for dietary intervention or therapy involving butyrate. It should also be considered, however, that although butyrate can induce apoptosis, there may be conditions in which cells lose their responsiveness to butyrate (Berry \& Paraskeva, 1988; Williams et al. 1990). This is consistent with the observation that two of the carcinoma cell lines we studied were resistant to butyrate-induced apoptosis (Hague et al. 1995). In some circumstances butyrate could, therefore, act as a tumour promoter by permitting clonal expansion of more malignant cell types. Whether an agent acts as an anti-tumour agent or a tumour promoter may depend on the genetic background of the cells and whether there are also specific mutagens in the diet (Paraskeva, 1992).

In summary, our finding that butyrate induces apoptosis in colo-rectal tumour cell lines could, in part, explain the protective nature of short-chain fatty acids. However, further work is required to determine the role of butyrate in the normal colon and whether under certain conditions high levels of butyrate can do more harm than good.

This research was funded by a programme grant from the Cancer Research Campaign of Great Britain.

\section{REFERENCES}

Arends, M. J. \& Wyllie, A. H. (1991). Apoptosis: mechanisms and role in pathology. International Review of Experimental Pathology 32, 223-254. 
Augeron, C. \& Laboisse, C. L. (1984). Emergence of permanently differentiated cell clones in a human colonic cancer cell line after treatment with sodium butyrate. Cancer Research 44, 3961-3969.

Berry, R. D. \& Paraskeva, C. (1988). Expression of carcinoembryonic antigen by adenoma and carcinoma derived epithelial cell lines: possible marker of tumour progression and modulation of expression by sodium butyrate. Carcinogenesis 9, 447-450.

Bicknell, G. R. \& Cohen, G. M. (1995). Cleavage of DNA to large kilobase pair fragments occurs in some forms of necrosis as well as apoptosis. Biochemical and Biophysical Research Communications 207, 40-47.

Bracey, T. S., Miller, J. C., Preece, A. \& Paraskeva, C. (1995). $\gamma$-Radiation-induced apoptosis in human colorectal adenoma and carcinoma cell-lines can occur in the absence of wild type p53. Oncogene 10, 2391-2396.

Burkitt, D. P. (1971). Epidemiology of cancer of the colon and rectum. Cancer 28, 3-13.

Chadwick, R. W. \& George, S. E. (1992). Role of the gastrointestinal mucosa and microflora in the bioactivation of dietary and environmental mutagens or carcinogens. Drug Metabolism Reviews 24, 425-492.

Clarke, A. R., Gledhill, S., Hooper, M. L., Bird, C. C. \& Wyllie, A. H. (1994). p53 dependence of early apoptotic and proliferative responses within the mouse intestinal epithelium following $\gamma$-irradiation. Oncogene 9 , 1767-1773.

Cummings, J. H., Pomare, E. W., Branch, W. J., Naylor, C. P. E. \& Macfarlane, G. T. (1987). Short chain fatty acids in human large intestine, portal, hepatic and venous blood. Gut 28, 1221-1227.

Deng, G., Liu, G., Hu, L., Gum, J. R. \& Kim, Y. S. (1992). Transcriptional regulation of the human placentallike alkaline phosphatase gene and mechanisms involved in its induction by sodium butyrate. Cancer Research 52, 3378-3383.

Gamet, L., Daviaud, D., Denis-Pouxviel, C., Remesy, C. \& Murat, J. C. (1992). Effects of short chain fatty acids on growth and differentiation of the human colon cancer cell line HT29. International Journal of Cancer 52, $286-289$.

Gavrieli, Y., Sherman, Y. \& Ben-Sasson, S. A. (1992). Identification of programmed cell death in situ via specific labelling of nuclear DNA fragmentation. Journal of Cell Biology 119, 493-501.

Hague, A., Elder, D. J. E., Hicks, D. J. \& Paraskeva, C. (1995). Apoptosis in colorectal tumour cells: induction by the short chain fatty acids butyrate, propionate and acetate and by the bile salt deoxycholate. International Journal of Cancer 60, 400-406.

Hague, A., Manning, A. M., Hanlon, K. A., Huschtscha, L. I., Hart, D. \& Paraskeva, C. (1993). Sodium butyrate induces apoptosis in human colonic tumour cell lines in a p53-independent pathway: implications for the possible role of dietary fibre in the prevention of large bowel cancer. International Journal of Cancer 55, 498-505.

Hague, A., Moorghen, M., Hicks, D., Chapman, M. \& Paraskeva, C. (1994). Bc1-2 expression in human colorectal adenomas and carcinomas. Oncogene 9, 3367-3370.

Hall, P. A., Coates, P. J., Ansari, B. \& Hopwood, D. (1994). Regulation of cell number in the mammalian gastrointestinal tract: importance of apoptosis. Journal of Cell Science 107, 3569-3577.

Heerdt, B. G., Houston, M. A. \& Augenlicht, L. H. (1994). Potentiation by short chain fatty acids of differentiation and apoptosis in human colonic carcinoma cell lines. Cancer Research 54, 3288-3294.

Hockenbery, D. M., Zutter, M., Hickey, W., Nahm, M. \& Korsmeyer, S. J. (1991). Bcl-2 protein is topographically restricted in tissues characterized by apoptotic cell death. Proceedings of the National Academy of Sciences, USA 88, 6961-6965.

Howe, G. R., Benito, E., Castelleto, R., Cornée, J., Estève, J., Gallagher, R. P., Iscovich, J. M., Deng-ao, J., Kaaks, R., Kune, G. A., Kune, S., L'Abbé, K. A., Lee, H. P., Lee, M., Miller, A. B., Peters, R. K., Potter, J. D., Riboli, E., Slattery, K. L., Trichopoulos, D., Tuyns, A., Tzonou, A., Whittemore, A. S., Wu-Williams, A. H. \& Zheng, S. (1992). Dietary intake of fibre and decreased risk of cancers of the colon and rectum - evidence from the combined analysis of 13 case-control studies. Journal of the National Cancer Institute 84, $1887-1896$.

Jass, J. R. (1985). Diet, butyric acid and differentiation of gastrointestinal tract tumours. Medical Hypotheses 18 , 113-118.

Kashtan, H., Stern, H. S., Jenkins, D. J. A., Jenkins, A. L., Thompson, L. U., Hay, K., Marcon, N., Minkin, S. \& Bruce, W. R. (1992). Colonic fermentation and markers of colorectal cancer risk. American Journal of Clinical Nutrition 55, 723-728.

Krajewski, S., Bodrug, S., Krajewska, M., Shabaik, A., Gascoyne, R., Berean, K. \& Reed, J. C. (1995). Immunohistochemical analysis of mcl-1 protein in human tissues - differential regulation of mcl-1 and bcl-2 protein-production suggests a unique role for mcl-1 in control of programmed cell-death in vivo. American Joumal of Pathology 146, 1309-1319.

Krajewski, S., Krajewska, M., Shabaik, A., Miyashita, T., Wang, H.-G. \& Reed, J. C. (1994a). 
Immunohistochemical determination of in vivo distribution of Bax, a dominant inhibitor of Bcl-2. American Journal of Pathology 145, 1323-1336.

Krajewski, S., Krajewska, M., Shabaik, A., Wang, H.-G., Irie, S., Fong, L. \& Reed, J. C. (1994b). Immunohistochemical analysis of in vivo patterns of Bcl-x expression. Cancer Research 54, 5501-5507.

Levin, B. (1992). Nutrition and colorectal cancer. Cancer 70, 1723-1726.

McIntyre, A., Gibson, P. R. \& Young, G. P. (1993). Butyrate protection from dietary fibre and protection against large bowel cancer in a rat model. Gut 34, 386-391.

Merritt, A. J., Potten, C. S., Kemp, C. J., Hickman, J. A., Balmain, A., Lane, D. P. \& Hall, P. A. (1994). The role of 553 in spontaneous and radiation-induced apoptosis in the gastrointestinal tract of normal and p53deficient mice. Cancer Research 54, 614-617.

Otaka, M., Singhal, A. \& Hakomori, S. (1989). Antibody-mediated targeting of differentiation inducers to tumor cells: inhibition of colonic cancer cell growth in vitro and in vivo. Biochemical and Biophysical Research Communications 158, 202-208.

Paraskeva, C. (1992). Colorectal cancer and dietary intervention. Lancet 339, 869-870.

Potten, C. S., Li, Y. Q., O'Connor, P. J. O. \& Winton, D. J. (1992). A possible explanation for the differential cancer incidence in the intestine, based on distribution of the cytotoxic effects of carcinogens in the murine large bowel. Carcinogenesis 13, 2305-2312.

Raff, M. C. (1992). Social controls on cell survival and death: an extreme view. Nature 356, 397-400.

Roediger, W. E. W. (1982). Utilization of nutrients by isolated epithelial cells of the rat colon. Gastroenterology $\mathbf{8 3}, 424-429$.

Rogers, A. E., Zeisel, S. H. \& Groopman, J. (1993). Diet and carcinogenesis. Carcinogenesis 14, $2205-2217$.

Sandler, R. S., Lyles, C. M., Peipins, L. A., McAuliffe, C. A., Woosley, J. T. \& Kupper, L. L. (1993). Diet and risk of colorectal adenomas: macronutrients, cholesterol, and fiber. Joumal of the National Cancer Institute 85, 884-891.

Scheppach, W. (1994). Effects of short chain fatty acids in gut morphology and function. Gut 35, Suppl. 1, S35-S38.

Scheppach, W., Bartram, H. P. \& Richter, F. (1995). Role of short chain fatty acids in the prevention of colorectal cancer. European Journal of Cancer 31A, 1077-1080.

Scheppach, W., Sommer, H., Kirchner, T., Paganelli, G.-M., Bartram, P., Christl, S., Richter, F., Dusel, G. \& Kasper, H. (1992). Effect of butyrate enemas on the colonic mucosa in distal ulcerative colitis. Gastroenterology 103, 51-56.

Silvester, K. R., Englyst, H. N. \& Cummings, J. H. (1995). Heal recovery of starch from whole diets containing resistant starch measured in vitro and fermentation of ileal effluent. American Joumal of Clinical Nutrition 62, 403-411.

Tsujimoto, Y., Cossman, J., Jaffe, E. \& Croce, C. M. (1985). Involvement of the bcl-2 gene in human follicular lymphoma. Science 228, 1440-1443.

Whitehead, R. H., Young, G. P. \& Bhathal, P. S. (1986). Effects of short chain fatty acids on a new colon carcinoma cell line (LIM 1215). Gut 27, 1457-1463.

Williams, A. C., Harper, S. J. \& Paraskeva, C. (1990). Neoplastic transformation of a human colonic epithelial cell line: in vitro evidence for the adenoma to carcinoma sequence. Cancer Research 50, 4724-4730.

Wyllie, A. H. (1980). Glucocorticoid-induced thymocyte apoptosis is associated with endogenous endonuclease activation. Nature 284, 555-556. 